\title{
Propaganda norteamericana en la Primera Guerra Mundial: Simplificación y deformación a través del cartel
}

\author{
Paula ReQueijo ReY \\ Universidad Complutense de Madrid \\ p.requeijo@ccinf.ucm.es \\ Carlos SAnz GonzÁLEz \\ Universidad Complutense de Madrid \\ csgsplata@hotmail.com \\ Carlos Del Valle Rojas \\ Universidad de la Frontera, Temuco (Chile) \\ delvalleufro@gmail.com
}

Recibido: 17 de junio de 2013

Aceptado: 24 de septiembre de 2013

\begin{abstract}
Resumen
La Primera Guerra Mundial representa un momento clave en la Historia de la Propaganda. Nunca antes en otro conflicto se había difundido propaganda con tanta intensidad. Estados Unidos, que decide entrar en el conflicto en abril de 1917, desarrolla una ingente labor propagandística a través del CPI o Comité Creel para conseguir que la opinión pública, partidaria de permanecer al margen, apoyara la guerra. Entre los numerosos vehículos de propaganda destinada a la retaguardia empleados por este Comité, nos ocuparemos del cartel ya que su impacto como medio de propaganda en este conflicto fue mayor que en ningún otro período de la Historia. El cartel dirigido a la retaguardia siguió fielmente dos de los principios fundamentales de la propaganda política: la simplificación y la deformación. Muchos de ellos presentan a un enemigo despiadado con unos valores perversos (Alemania) frente a un héroe con unos valores nobles (Estados Unidos) que se ve obligado a pararle los pies. Sirviéndose del estereotipo y las emociones, instrumentos básicos según Edward Bernays para cualquier campaña de propaganda exitosa, convencen a la opinión pública de la necesidad de participar en el conflicto.
\end{abstract}

Palabras clave: Primera Guerra Mundial; propaganda norteamericana; retaguardia; cartel; simplificación; deformación.

\section{Northamerican propaganda in the First World War: Simplification and distortion through poster}

\begin{abstract}
First World War represents a key moment in the History of Propaganda. Never before in another conflict propaganda had spread with such intensity. United States, which decide to enter the conflict in April 1917, developes a massive propaganda labor through the CPI or Creel Committee to ensure that public opinion, in favour of staying out of the war, support it. Among the many propaganda vehicles directed to the rear employed by this Committee, we will focus on the poster as its impact as a propaganda medium in this conflict was higher than in any other period of history. The poster directed to the rear faithfully followed two of the fundamental principles of political propaganda: simplification and distortion. Many of them have a ruthless enemy with evil values (Germany) against a hero with noble values (USA)
\end{abstract}


who is forced to stop him. Making use of the stereotype and emotions, basic tools for any successful propaganda campaign according to Edward Bernays, they convince the public of the need to participate in the conflict.

Key words: First World War; Northamerican propaganda; the rear; poster; simplification; deformation.

\section{Referencia normalizada}

Requeijo Rey, P.; Sanz González, C. y Del Valle Rojas, C. (2013). Propaganda norteamericana en la Primera Guerra Mundial: Simplificación y deformación a través del cartel. Historia y Comunicación Social, vol. 18, págs. 31-42.

Sumario: 1. Introducción. 2. Las técnicas de propaganda política básicas y la propaganda norteamericana. 2.1. Simplificación y deformación a través del cartel 3. Análisis de carteles 4. Conclusiones. 5. Bibliografía.

\section{Introducción}

El experto en propaganda Alejandro Pizarroso señala que la IGM es el primer conflicto bélico de la Historia en el que la retaguardia pasa a jugar un papel tan importante o más que el del frente debido a la necesidad de material bélico (1993). La propaganda dirigida a la retaguardia para concienciarla de que debía esforzarse para vencer en el conflicto fue fundamental. También lo fue la propaganda dirigida al exterior para conseguir nuevos aliados con el mismo objetivo. En este sentido, la propaganda británica dirigida a Estados Unidos fue decisiva para hacerle entrar en el conflicto del lado de los aliados en abril de 1917. Lo mismo ocurrió con la propaganda que los propios norteamericanos desarrollaron para conseguir que sus ciudadanos apoyaran la guerra.

Una semana después de que Estados Unidos se uniera al conflicto, el presidente Wilson pidió al periodista George Creel que dirigiera el Committee on Public Information, conocido como CPI o Comité Creel, que se encargó de organizar la propaganda. Tobin y Bidwell consideran que el CPI puede ser el responsable del "trabajo más eficaz de propaganda de guerra a gran escala que el mundo hubiera visto nunca" (Tobin y Bidwell, en Brown, 1981: 4-5).

Entre los profesionales que formaron parte de este Comité estaba el padre de las Relaciones Públicas, Edward Bernays, que comparte esta idea con Tobin y Bidwell. En sus libros Propaganda y Cristalizando la opinión pública expone algunas de las claves que, a su juicio, ha de seguir toda acción propagandística para ser exitosa y que la propaganda norteamericana de la Primera Guerra Mundial cumplió. Estas claves a las que se refiere Bernays pueden integrarse, a su vez, dentro de las cinco reglas o técnicas básicas de la propaganda política que veremos en el siguiente apartado.

Bernays cree que el éxito de la propaganda norteamericana durante la Primera Guerra Mundial marca un antes y un después en la Historia de Estados Unidos. El conflicto demuestra la capacidad de la propaganda para "disciplinar la mente pública". Su poder es tal que "se salda con la imposición de una disciplina en la mente pública 
tanto como un ejército impone la disciplina en los cuerpos de sus soldados" (Bernays, 2008: 33-34). Esto hace que personas con gran influencia social tomen conciencia de la importancia de emplear herramientas propias de este mecanismo para controlar a la opinión pública una vez que el conflicto finaliza.

El propio Bernays se sirvió del estereotipo, la estrategia de la asociación o la apelación a las emociones y el inconsciente para conseguir que determinadas corporaciones (desde American Tobacco a United Fruit Company), causas (desde la lucha contra la discriminación racial a la lucha contra el comunismo) o personas (desde los presidentes Woodrow Wilson, Calvin Coolidge o Dwight Eisenhower al tenor Enrico Carusso) gozaran del favor del público. No es de extrañar que su intuición a la hora de influir sobre las masas maravillara a dirigentes que debieron gran parte de su éxito a la propaganda como Adolf Hitler.

En este artículo nos ocuparemos de la propaganda norteamericana dirigida a la retaguardia, en concreto, aquella que utiliza como vehículo el cartel. Antes de la I Guerra Mundial ya se podían encontrar numerosos ejemplos de la utilización de carteles con fines publicitarios y propagandísticos. Esto viene dado por las ventajas que supone el formato con respecto a otros, como puede ser su reproducción masiva sin unos costes elevados, su capacidad para combinar textos, imágenes y todo tipo de recursos gráficos de forma efectiva $\mathrm{y}$, sobre todo, por la facilidad de transporte y exposición en lugares públicos.

A principios del siglo $\mathrm{XX}$, medios de comunicación masivos como la radio aún no estaban lo suficientemente popularizados como para ser utilizados con fines propagandísticos, por lo que los estamentos gubernamentales volcaron todos sus esfuerzos en el cartel. A finales del XIX, con las vanguardias europeas, vivió una etapa artísticamente prolífica con maestros como Henri Marie Raymond de Toulouse-Lautrec. Otros artistas que destacaron por sus carteles fueron Aubrey Beardsley, Jules Chèret o Alphonse Mucha (Garrido, 1997).

Por tanto podemos afirmar que, cuando comenzó la I Guerra Mundial, ya existía toda una tradición sobre el uso de los carteles con fines publicitarios, aunque antes y durante el conflicto bélico se potenciaron especialmente sus cualidades propagandísticas. El impacto del cartel como medio de propaganda en este conflicto fue mayor que en ningún otro período de la historia.

Los carteles en los que nos centraremos tratan de que los ciudadanos norteamericanos que cumplían con los requisitos necesarios (tener entre 18 y 45 años y buena salud) dejaran de ser retaguardia para convertirse en parte del frente y de que los que debían permanecer en la retaguardia, apoyaran el conflicto, principalmente a través de la compra de bonos para financiar las operaciones militares aliadas.

Para ello, el cartel se servirá de dos de las técnicas propagandísticas básicas a las que nos hemos referido: la simplificación y la desfiguración, representando a Alemania como un enemigo cruel frente a los Estados Unidos, el héroe capaz de pararle los pies con su participación y compromiso en el conflicto. 


\section{Las técnicas de propaganda política básicas y la propaganda norteamericana}

Siguiendo a Jean - Marie Domenach, Pizarroso expone cinco técnicas fundamentales de la propaganda política: la orquestación, el contagio o unanimidad, la trasfusión, la contrapropaganda, la simplificación y la desfiguración o engrandecimiento (1993).

La orquestación consiste en transmitir el mensaje a través de distintos vehículos. El Comité Creel se sirvió de noticias de prensa, carteles, obras de teatro, películas, lecciones en las escuelas, sermones en las iglesias, líderes de opinión y conferenciantes para lograr que la opinión pública apoyara la guerra.

Llama la atención el esfuerzo que realizó el organismo para coordinar a conferenciantes voluntarios. Consiguió que un total de 75.000 pronunciaron 750.000 discursos a favor de la guerra (Álvarez, 1983: 170). La duración de los mismos era breve: cuatro minutos por discurso, por lo que a los conferenciantes se les conocía como "Four Minute Men".

En cuanto a los líderes de opinión, reunieron a individuos prominentes que apoyaban la participación de EEUU en el conflicto. Este reclutamiento de líderes de opinión responde a uno de los instintos que distinguió el psicólogo William McDougall: el instinto gregario ${ }^{1}$. McDougall fue uno de los autores que influyó de forma decisiva en los planteamientos de Bernays.

El uso de líderes de opinión, la élite de los grupos, también está en línea con el principio de unanimidad o contagio: el tiempo que un determinado grupo tarda en asimilar un mensaje propagandístico es menor si éste lo han asumido primero los líderes.

La trasfusión se refiere a que la propaganda debe basarse en "un sustrato preexistente: una mitología nacional, o fobias y filias comunes y tradicionales" (Domenach, en Pizarroso, 1993: 35). Es cierto que los norteamericanos no sentían fobia hacia los alemanes antes de la Primera Guerra Mundial. Al contrario: los admiraban porque los veían como a un pueblo culto. La propaganda sobre las atrocidades de los alemanes les haría cambiar de opinión. Sin embargo, sí conecta con un aspecto de la mitología nacional: el destino manifiesto que complementa la Doctrina Monroe a la que, a su vez, amplía el Corolario de Theodore Roosevelt al Congreso el seis de diciembre de 1904. Dios les impone, primero, un destino que supone extenderse por el Norte del continente americano para fundar un sistema de libertades huyendo así de las maldades propias de Europa. Después, determina que se conviertan, en palabras del propio Roosevelt, en "policía internacional" teniendo la responsabilidad de intervenir en el hemisferio occidental si la libertad está en peligro (Requeijo, 2006).

La contrapropaganda norteamericana se dirigió fundamentalmente al frente alemán para tratar de que los soldados se rindieran. 


\subsection{Simplificación y deformación a través del cartel}

Veremos las otras dos estrategias básicas a través de los carteles dirigidos a la retaguardia.

El mensaje fue claro y simple: los alemanes cometen todo tipo de crueldades en Europa y, Estados Unidos, como defensor de la libertad no puede permitirlo. Identifican, por tanto, un enemigo contra el que lanzar sus críticas y, frente a él, sitúan a un héroe, Estados Unidos, frecuentemente representado a través de la figura del soldado en torno al que concentran las alabanzas.

La desfiguración o exageración se aprecia claramente en la misma representación de los soldados y dirigentes alemanes, que, como veremos, aparecen como seres capaces de las mayores barbaridades. En algunos carteles se llega a animalizar a los soldados alemanes que se asemejan más a primates que a seres humanos.

Lo expuesto entro dentro de lo que se conoce como atrocity propaganda. Para Pizarroso esta propaganda de atrocidades fue "el aspecto más significativo" de la propaganda de la Primera Guerra Mundial que se sirvió de masacres, mutilaciones y maltratos (1993). Los carteles norteamericanos dirigidos a la retaguardia son un gran ejemplo.

Las características del enemigo son indispensables para justificar el conflicto. No importa que para demostrar su falta de humanidad haya que mentir. A través de las atrocidades perpetradas por los alemanes se provocaban una serie de emociones en la población norteamericana. Entre ellas, destaca el miedo. La propaganda llegó a crear un "verdadero histerismo antialemana en la opinión pública" (Pizarroso, 1993: 249).

Siguiendo a Lakoff podemos afirmar que los carteles, al igual que otros vehículos propagandísticos, se convirtieron en metáforas del terror que constituyeron el argumento movilizador para apoyar la guerra. Proporcionaron estructuras conceptuales de forma masiva por lo que constituyeron un potente enmarcado:

Uno de los descubrimientos fundamentales de la ciencia cognitiva es aquel según el cual la gente piensa en términos de marcos y de metáforas - estructuras conceptuales - (...). Los marcos están en las sinapsis de nuestro cerebro, presentes físicamente bajo la forma de circuitos neuronales. Cuando los hechos no encajan en los marcos, los marcos se mantienen y los hechos se ignoran. (Hay quienes piensan que) bastará con que se puedan presentar todos los hechos ante la mirada pública para que toda persona racional saque la conclusión correcta. Se trata de una esperanza totalmente vana. El cerebro humano sencillamente no funciona así. El enmarcado cuenta. Los marcos, una vez que se atrincheran, es difícil que se desvanezcan (2003: 110).

Los alemanes despertaban el pánico de la población que, al pensar en víctimas inocentes o en los propios soldados norteamericanos que combatían en territorio enemigo, podía comprometerse con ellos a través de la compra de bonos y otras iniciativas.

En esta misma línea, está el instinto de belicosidad, otro de los siete instintos primarios según McDougall. Bernays no tiene reparos en reconocer lo útil que es 
"representar batallas contra males en los que el antagonista es personificado por el público" (2000: 93). Continúa con un tono más poético: "En los descansos de nuestra existencia hemos de salir de la audiencia, avanzar hasta el escenario y, como héroes, luchar por la victoria del bien sobre el mal. Hemos de llenar con el aliento de nuestras vidas este combate alegórico" (2000: 95).

Es una idea que también aparece en el libro La opinión pública de Walter Lippmann. El autor explica que, para persuadir a aquellos que no tienen interés en un tema o que les resulta lejano, debemos recurrir a "un factor de lucha, suspense y victoria" (2003).

Por otro lado, Bernays destaca que los propagandistas del Comité Creel, a los que llama "manipuladores de la opinión patriótica", utilizaron de forma acertada los estereotipos y las emociones para provocar una serie de reacciones en las masas ${ }^{2}$ contra la supuesta crueldad y excesos del enemigo (Bernays, 2008: 37). El recurso a las emociones es una estrategia de persuasión y la persuasión "como fenómeno comunicativo es inherente al hombre desde el momento en que éste es tal" (Pizarroso, 1993: 27). Aristóteles en su Retórica critica las artes anteriores a él por "ocuparse de triquiñuelas de abogado y atender ante todo a mover las emociones del espectador" (Tovar, en Aristóteles, 1990: IX). Cicerón considera que si la habilidad del músico se juzga a partir del sonido que produce con las cuerdas de la lira, la del orador se basa en cómo mueve los afectos de su auditorio (Tovar, en Aristóteles, 1990: V y VI).

Para Maffesoli la pasión "está (...) en el origen de toda vida política". Ofrece ejemplos tan distintos como el de "Luis XVI, que refuerza el poder por la gestión de las pasiones" y el del jefe de los indios Guayaki que "no puede ser reconocido como tal, más que si sabe influir en los sentimientos, los deseos y (...) el imaginario colectivo" (Maffesoli, 1992: 5). La propaganda es propia de la organización estatal y recurrir a las emociones para persuadir al público acompañándolas o no de argumentos racionales "ha sido y es" para el experto en propaganda Oliver Thomson "el único camino de la propaganda" (Thomson, en Pizarroso, 2003: 27).

La atrocity propaganda o propaganda de atrocidades a la que ya nos hemos referido, combina, precisamente, las emociones con el estereotipo.

El amor familiar - ternura también fue otro de los instintos que distingue McDougall usado en los carteles. Incluían imágenes en los que se identificaba patria y familia, en los que se sugería que los soldados aliados protegían a los más débiles, mujeres y niños, o en los que, en palabras del propio Bernays aparecía "un famélico huérfano belga" o "famélicos huérfanos austriacos y alemanes" (2000: 96).

\section{Análisis de carteles}

El apartado de pinturas y fotografía de la Biblioteca del Congreso estadounidense cuenta con una colección de 1.900 carteles relacionados con la I Guerra Mundial. Se realizaron entre 1914 y 1920 y, la mayoría, fueron elaborados en Estados Unidos. 
Entre los más populares está el "I want you for U.S. army" (Figura 2) de James Montgomery realizado en 1917 con el Tío Sam como protagonista. Este cartel buscaba que los ciudadanos que cumplían los requisitos para alistarse, lo hicieran cuanto antes. Es una copia que populariza el cartel británico "Your country needs you" (Figura1) ideado por Alfred Leete en 1914. Muestra a Horatio Kitchener, Secretario de Estado de Guerra entre 1914 y 1916. Su imagen sólo se ve subordinada por la palabra You (Tú). Se puede apreciar el poder de convicción y la inmediatez de este tipo de propaganda, puesto que sólo necesita una imagen y una frase para conseguir transmitir una idea clara y concisa a toda la población, pero dirigiéndose a la vez a cada uno de ellos individualmente. Ambos carteles emplazan al receptor al patriotismo. Como sostiene Sloterdijk (1999), la invocación de la patria implica una referencia no sólo lingüística, sino también territorial; de tal forma que la patria apela a la tierra que nutre a la vez que es depósito de los muertos. Quien reclama la patria reclama un derecho. De ahí su defensa extrema.

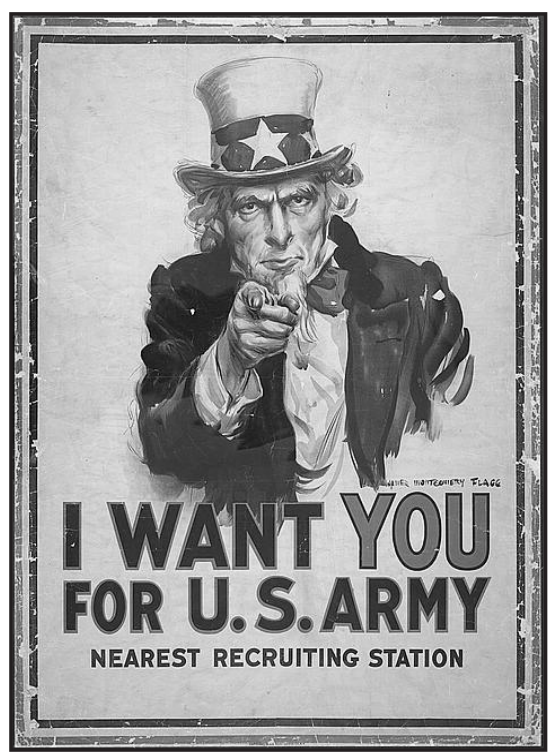

Figura 1. Cartel elaborado por James Montgomery en 1917

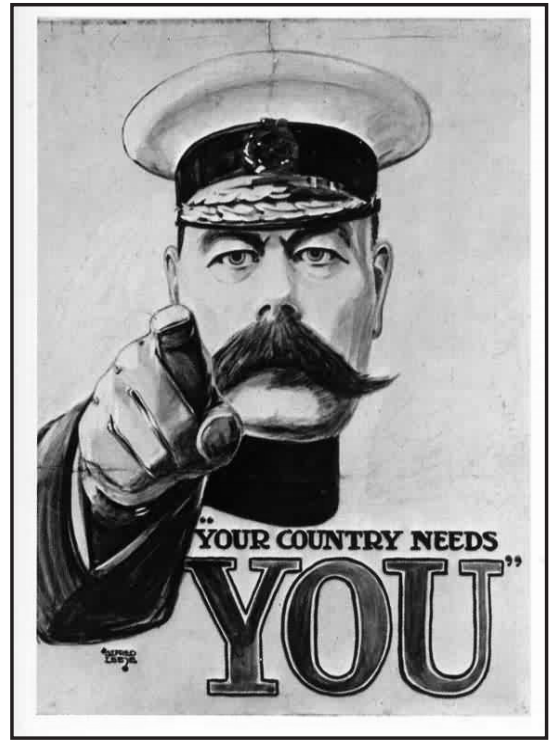

Figura 2. Cartel elaborado por Alfred Leete en 1914

Hay otros carteles que tratan de convencer al pueblo de la necesidad de alistarse en el ejército a través de la simplificación y la deformación, basándose en el estereotipo y las emociones a los que nos hemos referido en el apartado anterior. Emplean figuras retóricas como la hipérbole y la animalización para construir al enemigo o combinan estas figuras con la del contraste. Por ejemplo, representan a los alemanes como gorilas gigantes que arrasan con lo que hay en su camino y hacen daño a los más débiles o contraponen esta figura con la de un militar norteamericano al que habitualmente se acompaña de una bandera. También solían aparecer grupos de soldados, en un 
segundo plano, combatiendo por la causa y grandes titulares del tipo "Sé patriota" o “¿Qué estás haciendo para ayudar?". En otros casos encontramos a soldados aliados suplicando ayuda mientras son atacados con violencia. Se trata de la lucha entre los valores nobles (libertad y justicia) de los norteamericanos y los aliados frente a los valores perversos (opresión y abusos) de los alemanes.

El grafismo de estos carteles busca, ante todo, impactar al espectador con un solo vistazo y que recuerde las imágenes sin necesidad de una larga exposición. La gama cromática suele ser muy oscura, con un predominio de los negros o de marrones que añaden más dramatización a la escena dibujada. Además de esto, los textos que aparecen en ellos suelen ser muy cortos, de apenas un par de palabras como “¡Rápido!" o "La última llamada”, para no distraer la atención de la esclarecedora imagen principal.

Lo mismo ocurre, como ya habíamos comentado, con los carteles que tienen por finalidad la compra de bonos o cualquier otra actividad que sirviera para que los habitantes apoyaran el conflicto.

En el cartel de Walter Whitehead elaborado en 1918 (Figura 3) se puede comprobar cómo se repite la táctica utilizada por el cartel de Leete protagonizado por Horatio Kitchener. En esta ocasión, es el soldado el que se dirige directamente al espectador tras una lucha con un enemigo alemán bajo sus pies para alentar a comprar bonos de guerra (o de "libertad" como ellos los llaman) y así poder seguir luchando. Esta es una de las tácticas utilizadas por Bernays en sus campañas propagandísticas: se incluye una imagen con poder mediático (Bernays, 2008: 69) cuyo mensaje puede ser automáticamente asimilado por el espectador, en este caso un soldado en la batalla. A esto también ayuda la composición gráfica del cartel que incluye sólo los elementos necesarios para evitar distracciones.

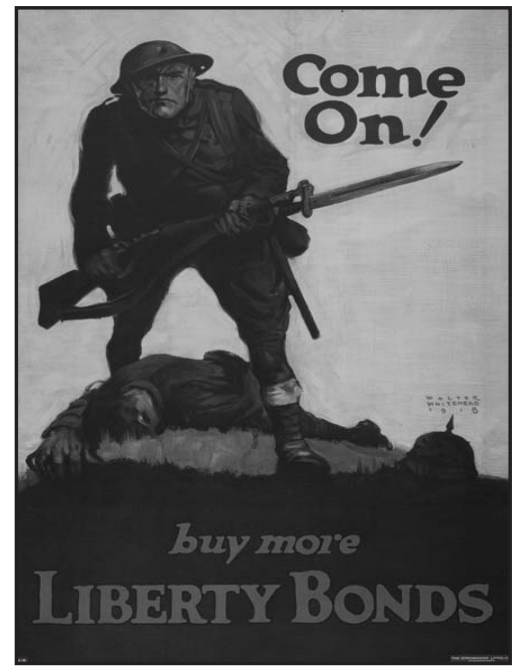

Figura 3. Cartel elaborado por Walter Whitehead en 1918

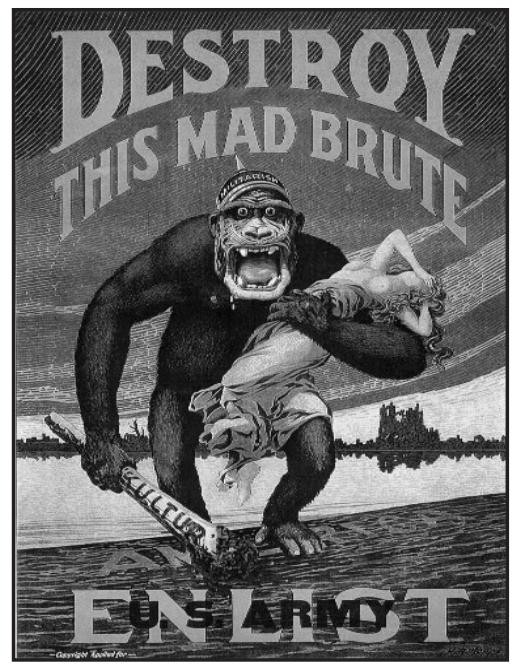

Figura 4. Cartel elaborado por James Hopps en 1917 
Otro ejemplo evidente de lo que hemos expuesto es el cartel "Destroy This Mad Brute" (Figura 4) de H.R. Hopps elaborado en 1917. Invita a los ciudadanos a alistarse en el ejército mostrando a los soldados alemanes como unos simios violentos y feroces capaces de raptar a cualquier mujer indefensa. El simio, con las manos manchadas de sangre y transportando una especie de cachiporra, mira directamente al espectador, haciéndole partícipe de la acción y dándole motivos para el alistamiento. De nuevo, se reduce al mínimo la utilización de textos y todo queda en manos del elocuente dibujo.

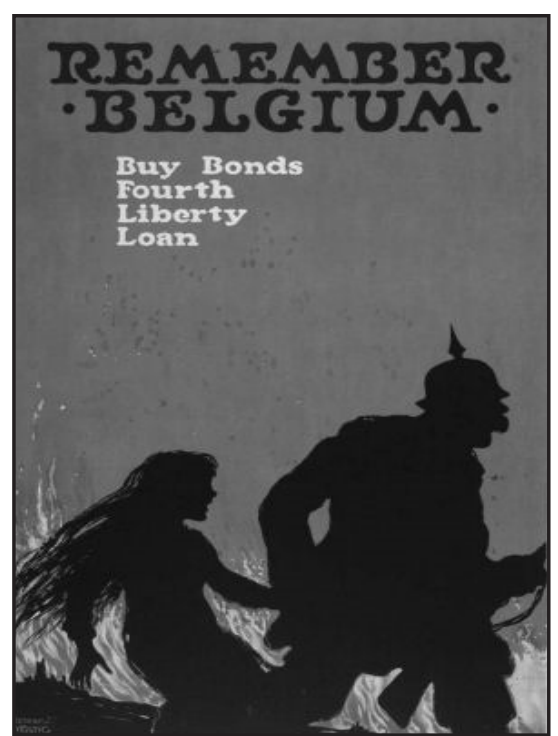

Figura 5. Cartel elaborado por Ellsworth Young en 1918

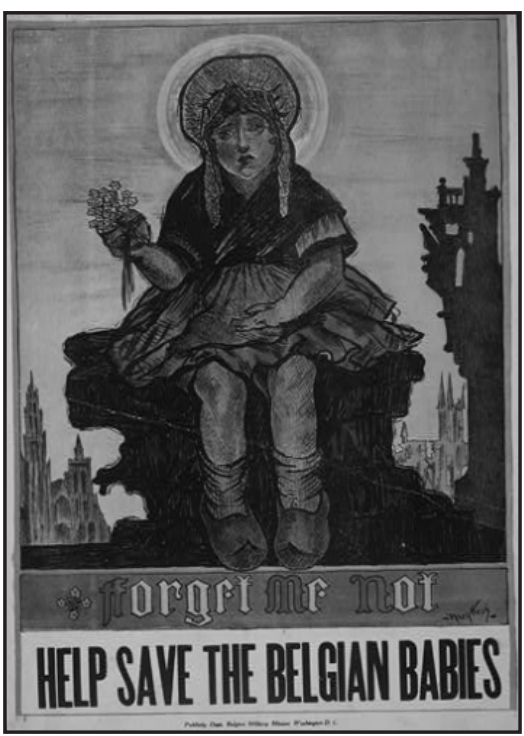

Figura 6. Cartel elaborado por Josef Pierre Nuittens en 1917

Otros carteles similares a los anteriores son "Remember Belgium" (Figura 5) elaborado por Ellsworth Young en 1918 y "Forget me not" (Figura 6) elaborado por Josef Pierre Nuittens en 1917. En el primero un soldado alemán al que se identifica por su casco puntiagudo (el pickelhaube) lleva a una niña belga de la mano tras dejar una ciudad ardiendo. En el segundo observamos a una niña pequeña con expresión de tristeza que sostiene un ramo de flores que se conocen como "no me olvides" jugando de ese modo con el nombre de la flor y el mensaje que se puede leer debajo. Precisamente, el objetivo de ambos carteles es que el receptor no olvide las atrocidades de los alemanes durante la invasión de Bélgica. El gobierno británico creó a finales de 1914 un comité de juristas e historiadores para analizar estas crueldades. El informe final se denominó Bryce Report y se tradujo a una treintena de idiomas. A pesar de que el informe exageraba los hechos y contenía mentiras, gozó de gran prestigio.

Los últimos dos carteles de la vasta colección de la Biblioteca del Congreso estadounidense que hemos seleccionado representan los estereotipos a los que nos hemos referido. "Beat back the hun with liberty bonds" (Figura 7), algo así como "Repele 
el ataque del huno con los bonos de guerra", elaborado por Frederick F. Strothmann en 1918, muestra a un soldado alemán que se asemeja a un monstruo. Su mirada es la de un zombi al que acaban de resucitar y que, sometido a la voluntad del que le ha devuelto la vida, sólo piensa en matar. Tanto la bayoneta que sostiene como su mano izquierda están bañadas en sangre. Se asocia a los alemanes con los hunos, sinónimo de salvajismo y violencia.

"If you can't enlist, invest" (Figura 8), "Si no puedes alistarte, invierte" elaborado por Winsor McCay muestra a un hercúleo soldado norteamericano que, junto a su espada y su escudo, lucha contra distintos monstruos que representan los males que Alemania va dejando allá por donde pasa: "devastation", devastación, "starvation", hambruna, "war", guerra, "pestilente", "pestilencia“ y "death", muerte. El soldado es una personificación de Estados Unidos (lo apreciamos en la banda que lleva alrededor de la cabeza y donde leemos "América") que puede intervenir en el conflicto gracias a los "bonos de libertad" (el escudo con el que se protege de los monstruos lo deja bien claro).

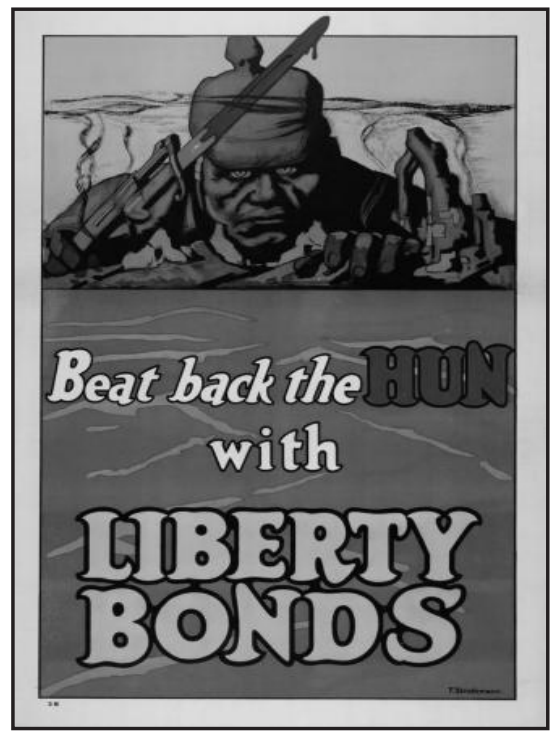

Figura 7. Cartel elaborado por Frederick F. Strothmann en 1918

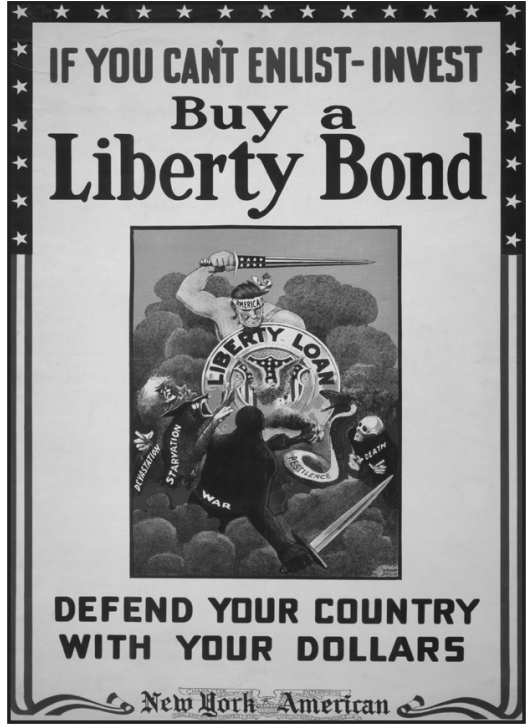

Figura 8. Cartel elaborado por Winsor McCay en 1918

\section{Conclusiones}

La propaganda fue fundamental para que el gobierno norteamericano lograra que la opinión pública, partidaria de no intervenir en la Primera Guerra Mundial, decidiera después apoyar el conflicto. El Comité Creel se sirvió de distintos vehículos de propaganda (orquestación) siendo el cartel uno de los más importantes gracias a la capacidad de su grafismo para impactar al receptor y grabar la imagen en su mente sin necesidad de una larga exposición. 
El análisis de los carteles destinados a la retaguardia revela el uso de los principios propagandísticos de la simplificación y la deformación. Muchos de ellos representan, a través de figuras retóricas (animalización, hipérbole), al enemigo sobre el que se concentraban todos los males: Alemania. Frente a él, se opone la figura del héroe, Estados Unidos, poseedor de virtudes como la libertad y la justicia. El héroe tiene el deber de proteger a los más débiles (potencias que Alemania ha invadido, como Bélgica) del villano.

Se trata de una idea que conecta con un aspecto de la mitología nacional (principio de trasfusión): el destino manifiesto, clave en la fundación de los Estados Unidos. Éste se identifica con la creación de un sistema de libertades frente a la iniquidad de Europa. Con Roosevelt la vigilancia de la libertad se extiende hasta el hemisferio occidental. Los EEUU son responsables de su garantía, teniendo el deber de intervenir cuando esta esté en peligro. Así es como se plantea, precisamente, la participación norteamericana en la primera Guerra Mundial. Los carteles muestran a soldados que luchan por defender la libertad y que llaman a la retaguardia a la acción: alístate si aún no lo has hecho o compra bonos de guerra.

La propaganda de atrocidades, fundamental en la Primera Guerra Mundial, tuvo su reflejo en los carteles. Los soldados alemanes aparecen portando armas (cachiporras, bayonetas) que están ensangrentadas, al igual que sus manos. Se recurre a las emociones (fundamentalmente miedo) y los estereotipos (los alemanes como hunos, monstruos o gorilas), elementos característicos de la propaganda de atrocidades.

\section{Bibliografía}

ÁLVAREZ, T. (1983). "Elementos para una reinterpretación histórica del siglo XX: el caso de la información-propaganda en Gran Bretaña 1914-1918”, en Boletín de la Real Academia de la Historia, tomo 180, cuaderno I, enero - abril, pp. 149-186. ARISTÓTELES (1990). Retórica. Madrid: Centro de Estudios Constitucionales. Edición del texto con aparato crítico, traducción, prólogo y notas por Antonio Tovar.

BERNAYS, E. (2000). Cristalizando la opinión pública. Barcelona: Ediciones Gestión 2000.

BERNAYS, E. (2008). Propaganda. Madrid: Melusina.

BROWN, D. (1984). "Government Public Affaires. Its Own Worst Enemy", en Public Relations Quarterly, $\mathrm{n}^{\circ} 26$, Spring term.

GARRIDO, M. (1997). "El Cartel Publicitario de Vanguardia", en Questiones Publicitarias: Revista de Métodos, Análisis y Estrategias de la Comunicación Publicitaria.. vol. 6, pp. 48-62.

LAKOFF, G. (2010). No pienses en un elefante. Lenguaje y debate politico. Madrid: Editorial Complutense.

LIPPMANN, W. (2003). La opinión pública. Madrid: Editorial C. de Langre. 
MAFFESOLI, M. (1992). La política y su doble. México: Instituto de Investigaciones Sociales de la UNAM.

PIZARROSO, A (1993). Historia de la propaganda. Madrid: Ediciones de la Uuniversidad Complutense, pp. 25-41 y 227- 253.

REQUEIJO, P (2006). "Dios, el beneficio económico y la creación del enemigo en La Cortina de Humo de Barry Levinson", en Revista de la Seeci, noviembre, $\mathrm{n}^{\circ}$ 13 , año XI.

SLOTERDIJK, P. (1999). "Patria y globalización. Notas sobre un recipiente hecho pedazos", en Revista Observaciones Filosóficas, Sección Artículos y Textos de Filosofía. Este artículo apareció originalmente en Spiegel Spezial, junio de 1999.

Colección Carteles de la Primera Guerra Mundial de la Biblioteca del Congreso estadounidense. Disponible en http://www.loc.gov/pictures/search/?st=grid\&co=wwipos. Consultas realizadas durante el mes de junio de 2013.

\section{Notas}

1 A finales del siglo XIX y principios del XX la psicología social trató de explicar la conducta humana centrándose en los instintos. William McDougall, uno de los pioneros de la psicología social, señaló la existencia de una serie de instintos. Unos eran primarios: temor, repulsión, curiosidad, belicosidad, auto-exhibición, auto-humillación y amor familiar. Otros, secundarios: gregario, individualista, adquisitivo, constructivo. Bernays insiste en la importancia, a la hora de moldear la opinión pública, de crear ideas que permitan beneficiarse de estos instintos.

La palabra instinto fue perdiendo fuerza dentro de la psicología social y dejó de emplearse porque se utilizó como una etiqueta para nombrar las distintas conductas humanas. Sin embargo, no explicaba el porqué ni las consecuencias de estas conductas. Tampoco quedaba claro si eran instintivas (heredadas) o aprendidas (hábitos). (Petri, H y Govern, J. (2009) Motivación. Teoría, investigación y aplicaciones. Madrid: Paraninfo) VVAA (2004) Introducción a la psicología social. Barcelona: Ediciones UOC).

2 Bernays cree que esta es una de las claves indispensables que ha de aplicarse en cualquier campaña de RRPP si se quiere tener éxito.

\section{Los autores}

Paula Requeijo Rey es doctora en Teoría de la Información y Personal Investigador Contratado (Programa FPU) en la Facultad de Ciencias de la Información de la Universidad Complutense de Madrid.

Carlos Sanz González es doctorando del Departamento de Comunicación Audiovisual y Publicidad II de la Facultad de Ciencias de la Información de la Universidad Complutense de Madrid.

Carlos del Valle Rojas es profesor de comunicación en la Facultad de Educación y Humanidades de la Universidad de la Frontera, Temuco, Chile. 